\section{The effect of posttrial ECS and footshock on the acquisition of a nonshock passive-avoidance response}

\section{RICHARD W. THOMPSON, RICHARD A. GALOSY, and GERALD W. MORLOCK* Western Washington State College, Bellingham, Wash. 98225}

Experiment 1, with a 2 by 2 factorial design of training/no training, ECS/no ECS, investigated the effect of ECS on the acquisition of a one-trial nonshock passive avoidance response. Results indicated passive-avoidance learning in trained Ss and that ECS produced nearly complete retrograde amnesia (RA) for the response. Experiment 2, using the same design and procedure, investigated the effect of posttraining footshock (FS) on the acquisition of the passive-avoidance response. Results indicated passive-avoidance behavior for groups receiving training and no FS, training and FS, and no training and FS. There was no evidence of RA produced by FS.

Electroconvulsive shock (ECS) is often employed in experiments investigating the physiological bases of memory. Early experiments frequently used multiple training trials and multiple ECSs, and although retrograde amnesia (RA) was often demonstrated in these studies, experiments by Coon \& Miller (1960) demonstrated that multiple ECSs also produced fear, which could account for the RA observed in many of these experiments. To avoid the conditioned fear effect of ECS, most experiments employing ECS now use some form of one-trial shock-motivated passive-avoidance task, such as the step-down box or the step-through box (Essman \& Alpern, 1964; Madsen \& McGaugh, 1961). The almost universal use of shock-motivated tasks in investigating the effects of ECS on learning and memory confounds ECS with shock motivation and seriously restricts the generality of the data obtained in those experiments. The present experiment investigated the effects of ECS on the acquisition of a nonshock passive-avoidance response (PAR).

\section{EXPERIMENT 1}

The experiment was a 2 by 2 factorial design with training (T) or no training (NT) and ECS or psuedo ECS (PECS) as factors.

\section{Subjects}

The Ss were four groups of 10 female albino rats $(\mathrm{N}=40), 90$ days of age, obtained from Sprague-Dawley, Madison, Wisconsin. The Ss had ad lib food and water throughout the experiment.

\section{Apparatus}

The apparatus (Thompson \& Galosy, 1969), a modified step-through box, was a covered box, $30.5 \mathrm{~cm}$ square and $40.6 \mathrm{~cm}$ high. The floor of the box, divided in half and hinged on each side to act as a trap

*Portions of Experiment 1 were reported at the 1969 Midwestern Psychological Association meeting in Chicago. following the trial on Day 1.

$$
\text { Results and Discussion }
$$

Mean STL in seconds for all groups for the 2 days are presented in Fig. 1 . An analysis of variance of the data for Day 1 indicated no significant differences among the four groups $(p>.05)$. To test for training and ECS effects, an analysis of variance was computed using the data for Days 1 and 2 with factors of training, ECS, and days. The main effects of days, ECS, and training were all significant, as were all of the interactions (all $F s \geqslant 5.98$, $\mathrm{df}=1 / 36, p<.05$ ). Subsequent analysis indicated that only Group T-PECS showed a significant increase in STL from Day 1 to Day $2(\mathrm{t}=6.11, \mathrm{df}=36, \mathrm{p}<.05)$.

Significant passive-avoidance learning in one trial was obtained using this task, learning which would appear to be as efficient and effective as that obtained with the typical shock-motivated tasks (Thompson \& Galosy, 1969). The effect of ECS was to produce nearly complete RA for the PAR. From these data it is possible to generalize the findings of the effects of ECS on passive-avoidance learning to noxious stimuli other than electric shock.

\section{EXPERIMENT 2}

Although ECS is the most frequent method used to investigate RA and the physiological basis of memory, other treatments such as anoxia (Thompson \& Pryor, 1956), $\mathrm{CO}_{2}$ (Quinton, 1966), hypothermia (Sudak \& Essman, 1962), anesthesia (Pearlman, Sharpless, \& Jarvik, 1961), and bilateral spreading cortical depression (Bures \& Buresova, 1963) have also been employed. All of these treatments produce gross changes in the normal activity of the brain, generally reflected by loss of consciousness, seizure activity, or both. Recently Jacobs \&

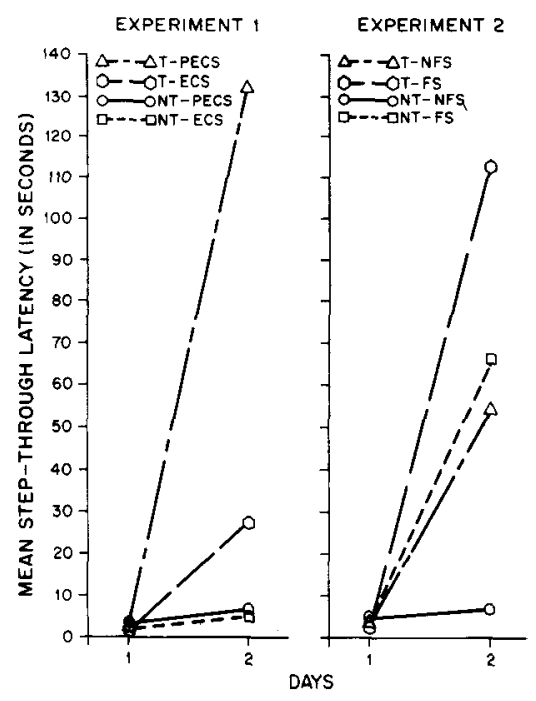

Fig. 1. Mean STL for all groups for both days in Experiments 1 and 2. 
Sorenson (1969) reported producing RA by a method which causes neither loss of consciousness nor seizure activity. Specifically, mice trained in a one-trial shock step-through PAR were dropped in either hot or cold water immediately after the footshock (FS). The first experiment in this paper demonstrated PAR acquisition in rats using falling into ice water as the noxious stimulus (Jacobs and Sorenson obtained similar data with mice) and that ECS produced RA for this response. Experiment 2 was designed to investigate the effect of posttraining-trial FS on the acquisition of a nonshock PAR.

\section{Apparatus}

The passive-avoidance apparatus was the same as that used in Experiment 1. The FS chamber was a Grason-Stadler rat chamber, $30 \mathrm{~cm}$ square and $28.5 \mathrm{~cm}$ high, with a grid floor of $0.3-\mathrm{cm}$ stainless steel rods, $1.3 \mathrm{~cm}$ center to center. The grid floor could be charged by a $2-\mathrm{sec}, 1.5 \mathrm{~mA}$ current from an Applegate (Model 250) stimulator through a Grason-Stadler scrambler.

\section{Procedure}

The training and testing procedures were identical to those of Experiment 1, except that FS or psuedo-FS was given in place of ECS or PECS. All Ss were placed on the platform on Day 1 and half were dropped as soon as they stepped onto the trap-door floor (trained Ss) and the other half were not (nontrained Ss). All Ss were placed in the shock chamber within $10 \mathrm{sec}$ after entering the training apparatus. Half of each trained and nontrained group received shock and the other half of each group received no shock. The resulting four groups were: trained and shocked (T-FS), trained and nonshocked (T-NFS), nontrained and shocked (NT-FS), and nontrained and nonshocked (NT-NFS). Step-through latencies were recorded for each $S$ on both Days 1 and 2 .

\section{Results and Discussion}

Mean STL for each group on the 2 days of testing are presented in Fig. 1. Analysis of variance of Day 1 data resulted in no significant differences among the groups $(p>.05)$, indicating they were well matched on Day 1. A second analysis of variance using the data of Day 1 and Day 2 with factors of training, shock, and days resulted in significant main effects of training, shock, and days, and interactions of Training by Days and Shock by Days (all Fs $\geqslant 6.99, \quad \mathrm{df}=1 / 58, \quad \mathrm{p}<.05$ ). Subsequent analysis of the Training by Days interaction (combining over shock conditions) indicated that both trained and nontrained groups showed significant increases in STL from Day 1 to Day 2 (both $t s \geqslant 2.52, \mathrm{df}=58, \mathrm{p}<.05$ ). There were no differences between trained and nontrained groups on Day 1, but they differed significantly on Day $2(t=3.59$, $\mathrm{df}=58, \mathrm{p}<.05)$. Analysis of the Shock by Days interaction (combining over training conditions) indicated that both shock and nonshock groups showed increase in STL from Day 1 to Day 2 (both $t s \geqslant 2.15$, $\mathrm{df}=58, \quad \mathrm{p}<.05)$. There were no differences between shocked and nonshocked groups on Day 1, but shocked Ss had significantly longer STLs than nonshocked Ss on Day $2(\mathrm{t}=4.62, \mathrm{df}=58$, $\mathrm{p}<.05)$.

Jacobs \& Sorenson (1969) have hypothesized that "a strong stimulus applied to the organism's exteroceptors shortly following a training trial interferes with the memory of the trial [p. 243]." They have also indicated that the intensity of the peripheral stimulus is directly related to the degree of neural activity and the amount of memory disruption. Besides the intensity of the disrupting stimulus, the only other characteristic it must have is to be different from the training stimuli. The shock stimulus employed in Experiment 2 would appear to meet the requirements for memory disruption stated by Jacobs and Sorenson, but the data contradict their hypothesis. The group trained and given postlearning FS had longer STLs than any other group; rather than producing RA, FS appeared to summate with the training stimuli of falling into ice water. The FS for untrained Ss produced increases in STLs which were equivalent to those for just training.

Although Experiment 2 was, in principle, reciprocal to that of Jacobs and Sorenson, there were a number of specific differences. First, rats were $S s$ in the present experiment, whereas Jacobs and Sorenson tested mice. Other experiments have also found differences between mice and rats, for example, on the permanence of RA produced by ECS (Luttges \& McGaugh, 1967; Zinkin \& Miller, 1967). Secondly, the learning-FS interval was longer than the interval Jacobs and Sorenson found effective in producing RA with postlearning water immersion. However, the 10-sec learning-FS interval of Experiment 2 was comparable to the learning-ECS interval found effective in producing RA in Experiment 1 . The results of Experiment 2 not only indicated failure to obtain RA, but demonstrated summation of the two kinds of aversive stimulation. Although FS was given in a room and apparatus different from that of learning and testing, it is possible that the handling of $S$ to place it in the FS chamber served as a CS for conditioning fuar and freezing responses so that on retesting $S$, the handling elicited freezing behavior indiscriminable from the training PAR. This interpretation to account for failure to obtain data congruent with the hypothesis of Jacobs and Sorenson is supported by the apparent passive-avoidance learning of shocked, but not trained, Ss.

If the hypothesis of Jacobs and Sorenson were correct, it would be difficult to understand how learning could ever take place. For example, you would expect, from their hypothesis, that the shock following a step-through response would disrupt the memory for the response and cues from the apparatus and no PAR learning to take place. Obviously PAR learning does occur as demonstrated by their own experiments. From the operant-conditioning literature, chaining of the FS and water immersion would have been predicted for the Jacobs and Sorenson experiment (as in Experiment 2), rather than RA for the FS.

\section{REFERENCES}

BUREŠ, J., \& BUREŠOVÁ, O. Cortical spreading depression as a memory disturbing factor. Journal of Comparative \& Physiological Psychology, 1963, 56, 268-272.

COONS, E. E., \& MILLER, N. E. Conflict versus consolidation of memory traces to explain "retrograde amnesia" produced by ECS. Journal of Comparative \& Physiological Psychology, 1960, 53, 524-531.

ESSMAN, W. B., \& ALBERN, H. Single trial conditioning: Methodology and results with mice. Psychological Reports, 1964, 14, $731-740$.

JACOBS, B., \& SORENSON, C. Memory disruption in mice by brief posttrial immersion in hot or cold water. Journal of Comparative \& Physiological Psychology, 1969, 68, 234-244.

LUTTGES, M. W., \& McGAUGH, J. L. Permanence of retrograde amnesia produced by electroconvulsive shock. Science, 1967, $156,408-410$.

MADSEN, M. C., \& McGAUGH, J. L. The effect of ECS on one-trial avoidance learnirg. Journal of Comparative \& Physiological Psychology, 1961, 54, 522-523.

PEARLMAN, C. A., SHARPLESS, S. K., \& JARVIK, M. E. Retrograde amnesia produced by anesthetic and convulsant agents. Journal of Comparative \& Physiological Psychology, $1961,54,109-112$

QUINTON, E. C. Retrograde amnesia induced by carbon dioxide inhalation. Psychonomic Science, 1966, 5, 417-418.

SUDAK, F. N., \& ESSMAN, W. B. Impairment of retention as a function of postconditioning hypothermia. Federation Proceedings, 1962, 21, 225. (Abstract)

THOMPSON, R. W., \& GALOSY, R. A one-trial non-shock passive avoidance task for rats. Behavior Research Methods \& Instrumentation, 1969, 1, 227.

THOMPSON, R., \& PRYER, R. S. The effects of anoxia on the retention of a discrimination habit. Journal of Comparative \& Physiological Psychology, 1956, 49, 297-300.

ZINKIN, S., \& MILLER, A. Recovery of memory after amnesia induced by electroconvulsive shock. Science, 1967. 155, 102-103. 